\title{
MONSTRUOS DE VERDAD. UN VASO ARQUEOLÓGICO CON DOS CABEZAS EN EL MUSEO DE LA PLATA (ARGENTINA)
}

\author{
REAL MONSTERS. TWO-HEADED ARCHEOLOGICAL VASE IN LA PLATA \\ MUSEUM (ARGENTINA)
}

Ana Igaretá, Guillermo López \& Cecilla Morganc

Desde hace miles de años la iconografía andina ha presentado imágenes de animales con diseños en ocasiones naturalistas y otras fantásticos, y la arqueología ha propuesto múltiples interpretaciones sobre el origen y función de cada conjunto. En el presente trabajo se analizan las características de un recipiente cerámico serpentiforme con dos cabezas hallado en Catamarca, Argentina, incluido en las colecciones del Museo de La Plata. El abordaje de la pieza desde una perspectiva zoológica permite proponer que no se trata de un bicéfalo sino de la representación de dos colúbridos en apareamiento.

Palabras clave: Arqueología andina, Representaciones zoomorfas, Abordaje biológico.

For thousands of years, Andean iconography has included images of animals with at times naturalistic and at others fantastical designs, and archeologists have offered multiple interpretations of the origin and function of each assemblage. This paper offers an analysis of the characteristics of a ceramic vessel with the form of a two-headed snake. It was discovered in Catamarca, Argentina and is now part of the Museo de La Plata collection. Using a zoological perspective, we find that the piece is not in fact a two-headed snake but instead a representation of two mating colubrid snakes.

Keywords: Andean archeology, Zoomorphic representations, Biological approach.
Venus para él era, una y otra, conocida pues de unas grandes serpientes uniéndose en la verde espesura, sus dos cuerpos a golpe de su báculo había violentado y, de varón, cosa admirable hecho hembra siete otoños pasó.

(Ovidio, "Las metamorfosis", en referencia a Tiresias y a los drásticos efectos que causó en él ver a dos serpientes copulando).

\section{CONSIDERACIONES GENERALES}

Desde hace más de 5000 años, diversas culturas del área andina meridional han mostrado un sostenido interés por la producción de diseños que remiten al cuerpo o la silueta de animales (Guzmán 2014). Imágenes de una extensa variedad de reptiles, anfibios, aves y mamíferos, particularmente camélidos y felinos, están presentes en toda la región, tanto en

A Ana Igareta, ConicET-División Arqueología, Facultad de Ciencias Naturales y Museo, Universidad Nacional de La Plata. E-mail: aigareta@gmail.com

B Guillermo M. López, División Paleontología de Vertebrados, Facultad de Ciencias Naturales y Museo, Universidad Nacional de La Plata. E-mail: glopez@fcnym.unlp.edu.ar

c Cecilia C. Morgan, conicet-Sección Mastozoología, División Zoología Vertebrados, Facultad de Ciencias Naturales y Museo, Universidad Nacional de La Plata. E-mail: cecilia.morgan@gmail.com 
soportes muebles -cerámica, piedra, textiles, madera, calabazas-, como inmuebles - pinturas y grabados rupestres, geoglifos, murales- (Clarkson \& Valenzuela 2015: 1). Parte de estas figuras son interpretadas como diseños naturalistas cuyos rasgos reproducen, con relativa fidelidad, los de animales reales; otras, en cambio, son consideradas representaciones de seres fantásticos en los que frecuentemente se combinan atributos zoomorfos y antropomorfos o caracteres de diferentes especies en un mismo individuo (Velandia 2011: 3). La arqueología ha proporcionado múltiples interpretaciones para uno y otro conjunto atribuyéndoles funciones identitarias, ornamentales, religiosas, rituales y/o propiciatorias de acuerdo con su contexto de origen, y elaborado diversas propuestas acerca del significado que la imagen de cada grupo de animales tuvo en el mismo. Por otra parte, algunos autores han dado cuenta de la "alta iconicidad" que exhiben muchos elementos arqueológicos zoomorfos, entendiendo por ello la estrecha relación de semejanza que mantienen con los animales representados (Gallardo \& Yacobaccio 2007: 10), mientras que otros han señalado que, pese a su semejanza, debe tenerse en cuenta que las imágenes distan mucho de ser retratos fieles de sus referentes faunísticos (Berenguer 2007: 21).

En lo que se refiere a la República Argentina, los registros más tempranos de iconografía zoomorfa se remontan a unos 3000 años atrás, con la aparición de las primeras escenas de caza y pastoreo de camélidos en el arte rupestre de la puna (Aschero et al. 1991, Núñez et al. 2006). Luego, hacia el $600 \mathrm{AC}$, distintos grupos del Noroeste del país comenzaron la producción de cerámicas con imágenes de animales (Bugliani \& Pereyra 2012) que continuó, como parte de tradiciones muy diversas, hasta el siglo xvi. Dichas imágenes aparecen pintadas, grabadas o incisas en un porcentaje mayoritario de las piezas, abundando también los recipientes con pequeños apéndices modelados a modo de cabezas, alas y colas o rabos. En cambio, son menos frecuentes las representaciones volumétricas completas en las que todo el objeto toma la forma del cuerpo del animal, destacándose en la región los vasos modelados que representan animales con cuatro patas y dientes prominentes y exagerados, atribuidos a culturas tempranas como Ciénaga y Condorhuasi (González 1983: 259). ${ }^{1}$ Si bien las características de las piezas zoomorfas han sido revisadas en detalle por la arqueología argentina desde hace más de un siglo (Raffino 1994: 14), los conjuntos con representaciones fantásticas parecen haber atraído mayor atención que las naturalistas, siendo escasos en el país los trabajos que intentaron un estudio sistemático de los rasgos biológicos de los animales representados. El análisis desarrollado por Kligmann, Albino y Díaz supone un muy interesante aporte en tal sentido, al analizar la correspondencia entre ciertos motivos iconográficos presentes en piezas cerámicas con las características biológicas de un grupo de reptiles que habita en la región de donde proceden las mismas (Kligmann et al. 2013).

En el marco de un ejercicio interdisciplinario orientado a analizar material arqueológico desde una perspectiva estrictamente biológica, profesionales de distintas divisiones científicas del Museo de La Plata (Buenos Aires, Argentina) realizan desde hace más de dos años un estudio de piezas pertenecientes a las colecciones arqueológicas que presentan rasgos zoomorfos, aplicando para ello criterios de taxonomía sistemática. La actividad busca explorar el aporte de un abordaje zoológico al estudio de representaciones arqueológicas de animales, intentando avanzar en la identificación de las especies involucradas en los diseños y en la elaboración de una primera propuesta acerca de su contexto ambiental de procedencia (Igareta et al. 2017: 53). Ello no implica desconocer o negar el carácter de producción mediatizada por los parámetros simbólicos de la cultura a la que pertenece el hacedor de la cerámica (Troncoso 2005: 114), sino simplemente ahondar en el potencial de dicha producción como fuente de información biológica.

Durante los trabajos se relevó la presencia de un pequeño recipiente cerámico cuya forma remite, a primera vista, a una serpiente de dos cabezas enroscada sobre sí misma y que en su ficha de inventario aparece descrita como "serpiente bicéfala". Un análisis zoológico de la pieza permitió proponer, en cambio, que se trata de una representación de dos serpientes copulando, y que su morfología y ornamentación reproducen en detalle sistemático rasgos de los organismos al punto de hacer posible su identificación específica. Si bien se trata de una propuesta hipotética y como tal susceptible de discusión, el ejercicio puso de relieve el potencial que este tipo de análisis tiene para el estudio de la fauna con la que poblaciones del pasado interactuaron y tuvieron contacto. 


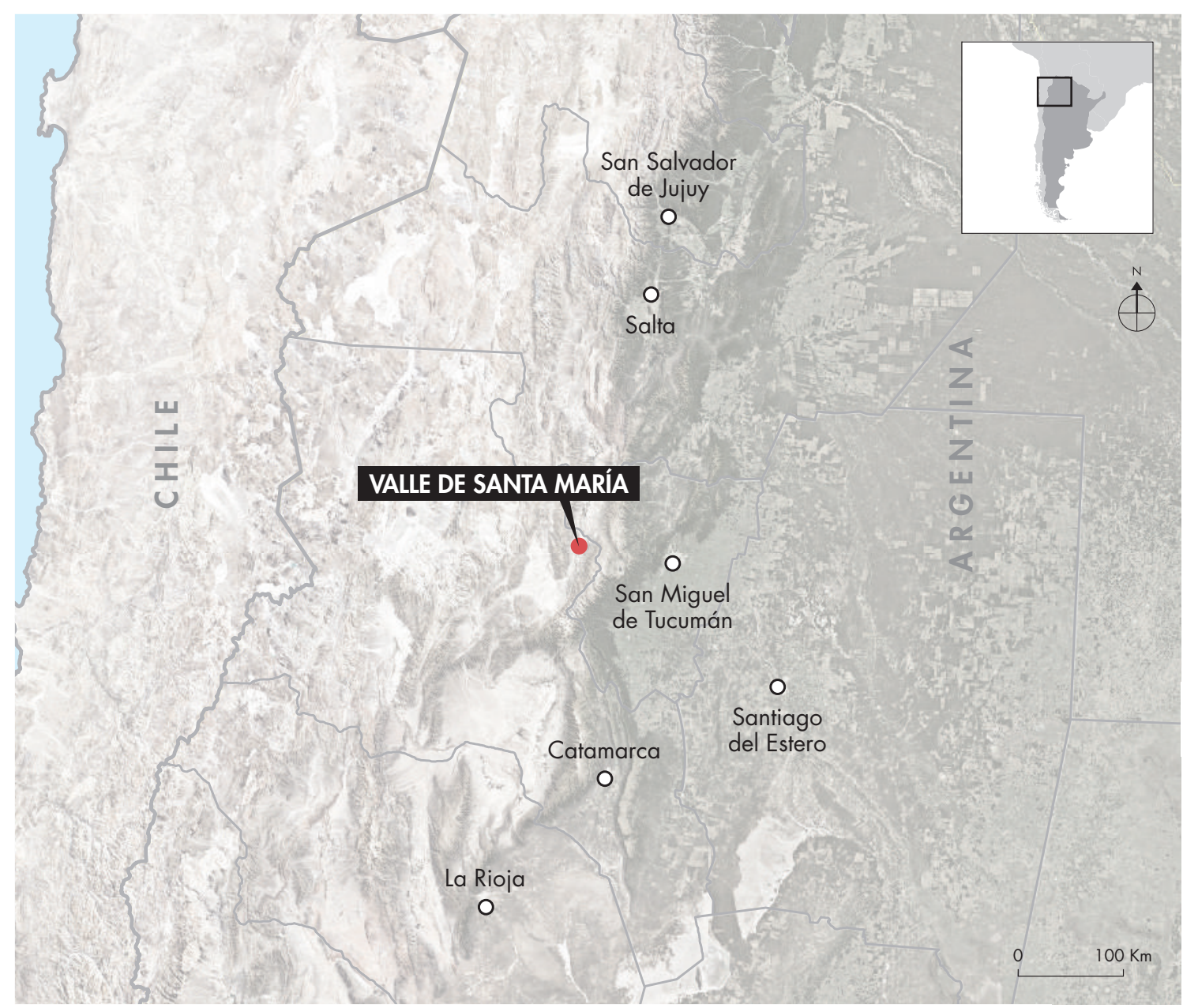

Figura 1. Detalle de la ubicación del Valle de Santa María en la Provincia de Catamarca, en el Noroeste de la República Argentina. Figure 1. Map showing location of the Santa María Valley in Catamarca Province, Northwest Argentina.

\section{La pieza}

En 1922 un equipo de exploradores contratados por el empresario Benjamín Muniz Barreto para obtener antigüedades excavó un conjunto de tumbas ubicadas en el sitio Famabalasto, en el Departamento de Santa María, provincia de Catamarca (fig. 1). ${ }^{2}$ En uno de esos entierros, y como parte del ajuar de la tumba de un individuo adulto, se recuperó un "vasito serpentiforme con decoración borrosa” al que se asignó el número 244 en el registro de campo, y que fue ingresado al Museo como pieza MLP-Ar-(n)5386 cuando la institución compró la colección en 1933 (Balesta \& Zagorodny 2000: 43).

Sus características tecnomorfológicas y el contexto en que fue recuperado permiten estimar que se trata de una pieza de tradición santamariana, estilo que se desarrolló en los valles del sur de la provincia de Salta y norte de Catamarca y Tucumán entre los siglos XI y XVI, y que se caracterizó por la manufactura cerámica de urnas, pucos y figurillas modeladas con decoración pintada (Nastri 2008: 11). Su iconografía abunda en diseños antropo y zoomorfos, teniendo las serpientes un rol protagónico en estos últimos (Nastri \& Coll 2010: 729).

El recipiente en cuestión mide $7,4 \mathrm{~cm}$ de diámetro y $3,5 \mathrm{~cm}$ de altura, y presenta una abertura superior de $2,3 \mathrm{~cm}$ de diámetro. Sobre uno de sus laterales se proyectan dos cabezas de serpientes modeladas, de contorno triangular, ligeramente superpuestas y con sus bocas y ojos incisos. El ancho máximo de la cabeza inferior es de 2,45 cm mientras que la de arriba es de 


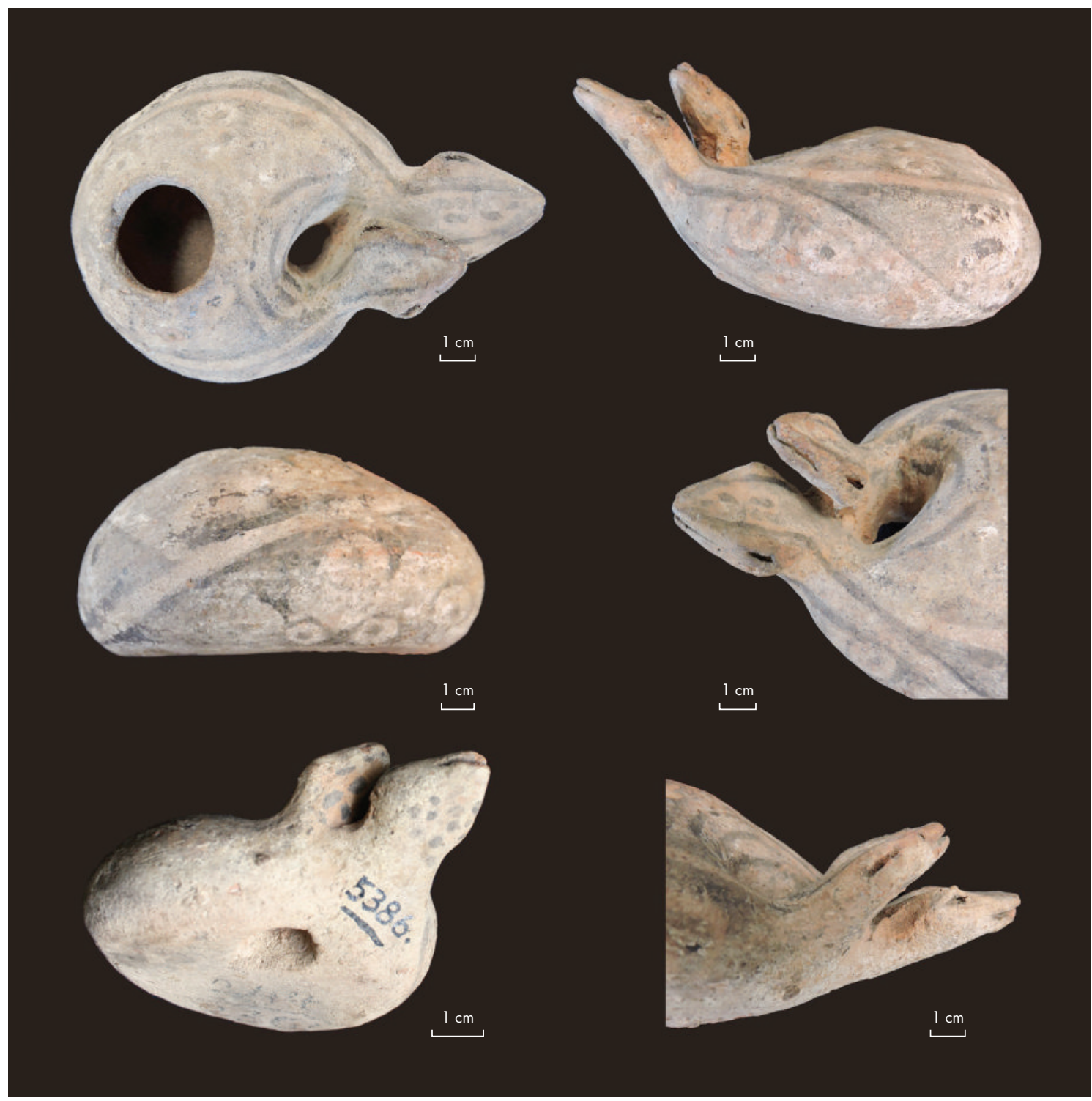

Figura 2. Seis vistas de la pieza. Nótese el diseño que la ornamenta y la forma y posición relativa de las cabezas. (Fotografías de los autores). Figure 2. Six views of the piece. Note the decorative design and shape and the relative position of the two head. (Photos by the authors).

2,17 cm. La superficie de la pieza presenta decoración pintada en blanco y negro, con un diseño de dos rayas negras de unos 2 a $3 \mathrm{~mm}$ de ancho, que se extienden por la circunferencia de la pieza y hasta las cabezas de los animales. A los lados de las rayas se observan pequeños círculos concéntricos pintados en tonos de negro, de unos $8 \mathrm{~mm}$ de diámetro, los externos más claros y los internos más oscuros. La base del recipiente no está ornamentada, pero sí la cara ventral de ambas cabezas, que presentan pequeñas manchas pintadas en negro de unos 2,5 mm de diámetro (fig. 2).

Si bien la pieza no ha sido objeto de un estudio arqueológico sistemático, su morfología general remite a la de un "vasito lliptero", un recipiente destinado a contener la llipta de la coca, una masa formada por cal y ceniza usada para potenciar el contenido de los alcaloides de la planta. Vasos de dimensiones y estilo semejantes se encuentran en las colecciones del Instituto 

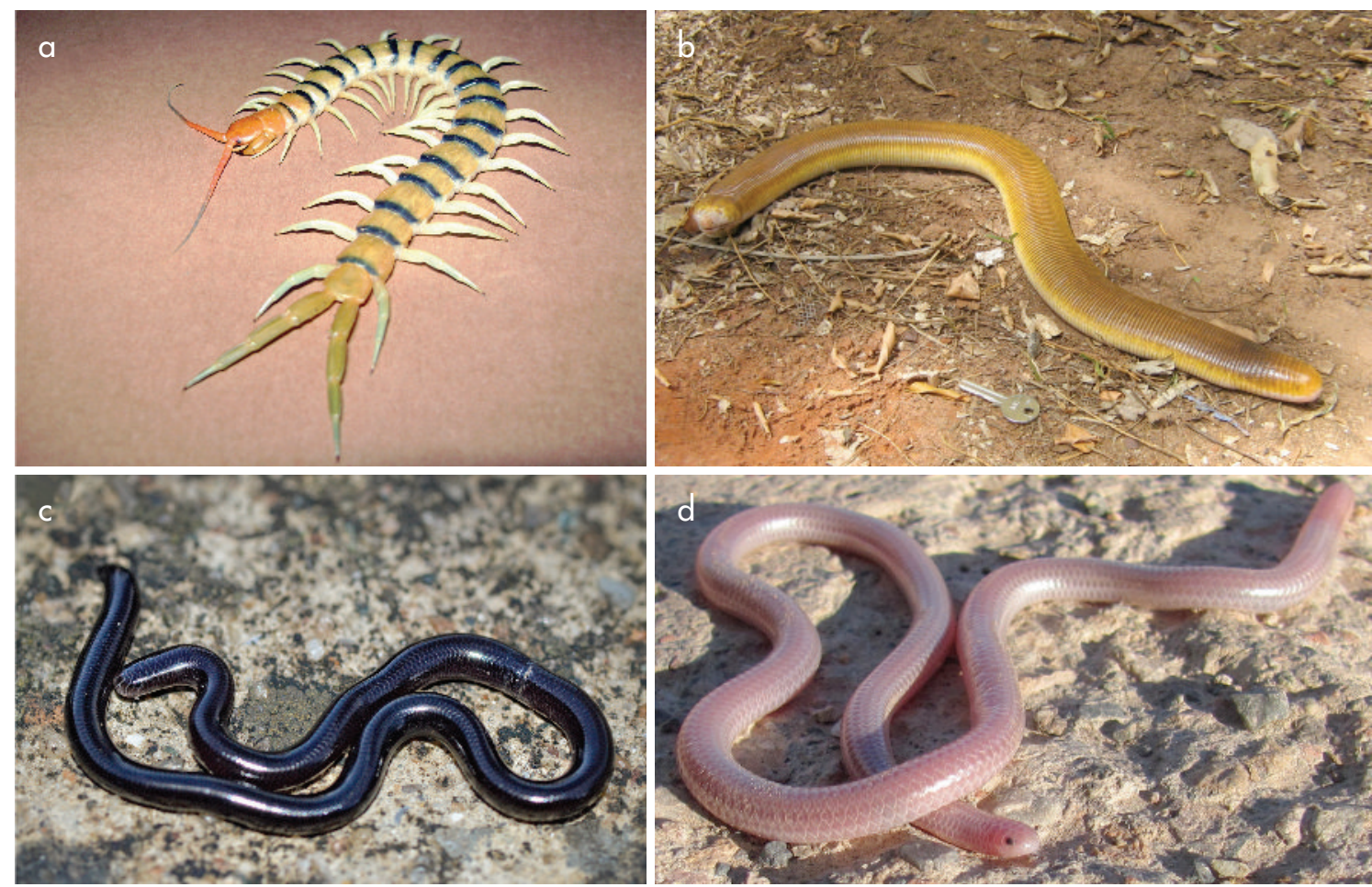

Figura 3. Diversos especímenes cuyo aspecto remite al de animales de dos cabezas: a) escolopendra; b) anfisbena; c-d) pequeños ofidios de vida subterránea. (Fotografías: a) Bill y Mark Bell; b) Diogo B. Provete; c) Alexandre Roux; d) Jonathan Hakim). Figure 3. Species similar in appearance to the two-headed ceramic figure: $a)$ scolopendra; $\boldsymbol{b}$ ) anphibenae; $\boldsymbol{c}$-d) small burrowing ophidia. (Photos: a) Bill $y$ Mark Bell; b) Diogo B. Provete; c) Alexandre Roux; d) Jonathan Hakim).

de Arqueología y Antropología, San Pedro de Atacama (Horta com. pers. 2017), y se ha propuesto que podrían provenir del Noroeste Argentino (Tarragó 1989). Hasta donde se tiene registro, no existe otra pieza de características semejantes en las colecciones del Museo de La Plata. Solo un pequeño fragmento cerámico perteneciente a la colección Moreno, que presenta dos cabezas de ofidio modeladas que divergen aparentemente de un mismo cuerpo, podría constituir una excepción en tal sentido, pero lamentablemente el grado de deterioro que presenta la pieza impide lograr una identificación sistemática y obtener mayores detalles.

\section{Análisis e identificación}

Descritas por primera vez por Juan Bautista Ambrosetti en el siglo XIX, los diseños pintados con serpientes y serpientes de dos cabezas abundan en la iconografía santamariana y su presencia constituye uno de los rasgos diagnósticos para la identificación de las manufacturas de esta cultura arqueológica (Ambrosetti 1896: 27), aunque las piezas volumétricas ofidiomorfas son mucho menos frecuentes. El significado potencial de tales representaciones en esta y otras culturas del área andina ha sido objeto de extensas discusiones entre los arqueólogos, quienes propusieron alternativamente que se trata de imágenes que aluden a entidades sobrenaturales como dragones (Lafone Quevedo 1908), serpientes bicéfalas (Ambrosetti 1896), o anfisbenas mitológicas (González 1998). Otros trabajos, en cambio, estimaron que se trata de diseños que aluden a ejemplares de animales en los cuales resulta difícil diferenciar cabeza y cola, tales como las escolopendras (invertebrados quilópodos vulgarmente conocidos como ciempiés, Velandia 2011: 12) o un grupo de reptiles escamados ápodos generalmente llamados viboritas ciegas o anfisbenas (Kligmann et al. 2013) (fig. 3).

Resulta interesante señalar que, si bien la mayor parte de los investigadores que se ocuparon del tema para el área andina consideraron que las representa- 

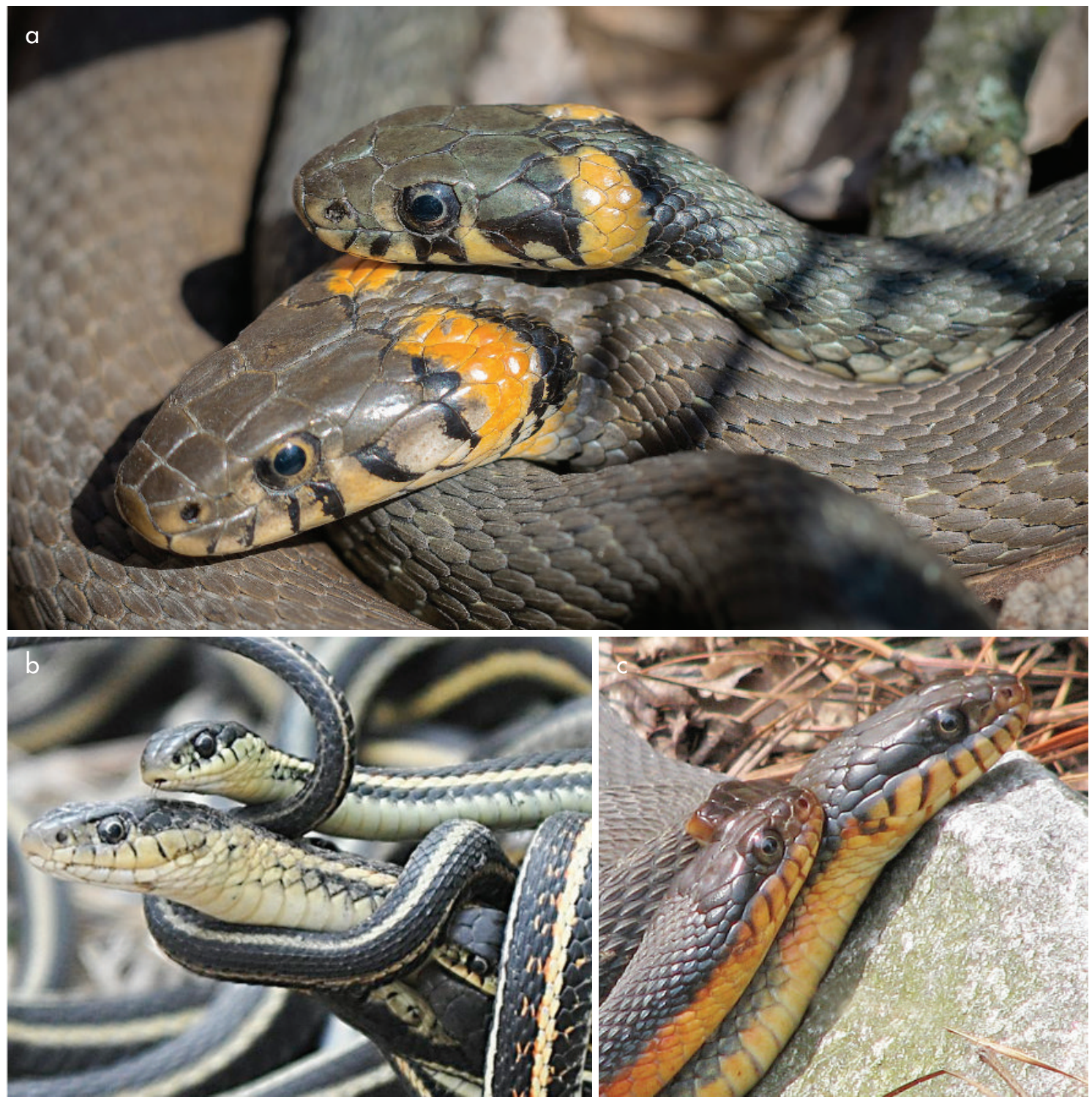

Figura 4. Culebras en apareamiento. Nótese que el macho es de menor tamaño, situación frecuente en la familia Colubridae. (Fotografías: a) de uso libre; b) Oregon State University; c) Vicki DeLoach). Figure 4. Snakes mating. Note that the male is smaller, as is frequently the case with the Colubridae family. (Photos: $\boldsymbol{a})$ public domain; $\boldsymbol{b}$ ) Oregon State University; $c$ ) Vicki DeLoach).

ciones de serpientes con dos cabezas corresponden a animales míticos o fantásticos, el nacimiento y desarrollo de serpientes con dos cabezas es un hecho registrado en la naturaleza, aunque tales cabezas nunca se encuentran ubicadas en extremos opuestos del cuerpo del animal. Tal condición, denominada dicefalismo o somatodicotomía, puede ocurrir como resultado de alteraciones del desarrollo embrionario, cambios en la temperatura durante el tiempo de incubación, contaminación ambiental, hibridación y depresión endogámica (Wallach 2007). Textos tan tempranos como los de Aristóteles, del 350 AC (Aristóteles [1812]) o el de Aelianus Tacticus, del 250 AC (Aelianus [1971]), ya mencionaron el fenómeno.

En el caso de la pieza MLP-Ar-(n)5386, un análisis pormenorizado permitió observar que los rasgos representados no remiten a un organismo bicéfalo sino a los de dos serpientes con sus cuerpos entrelazados, tal 


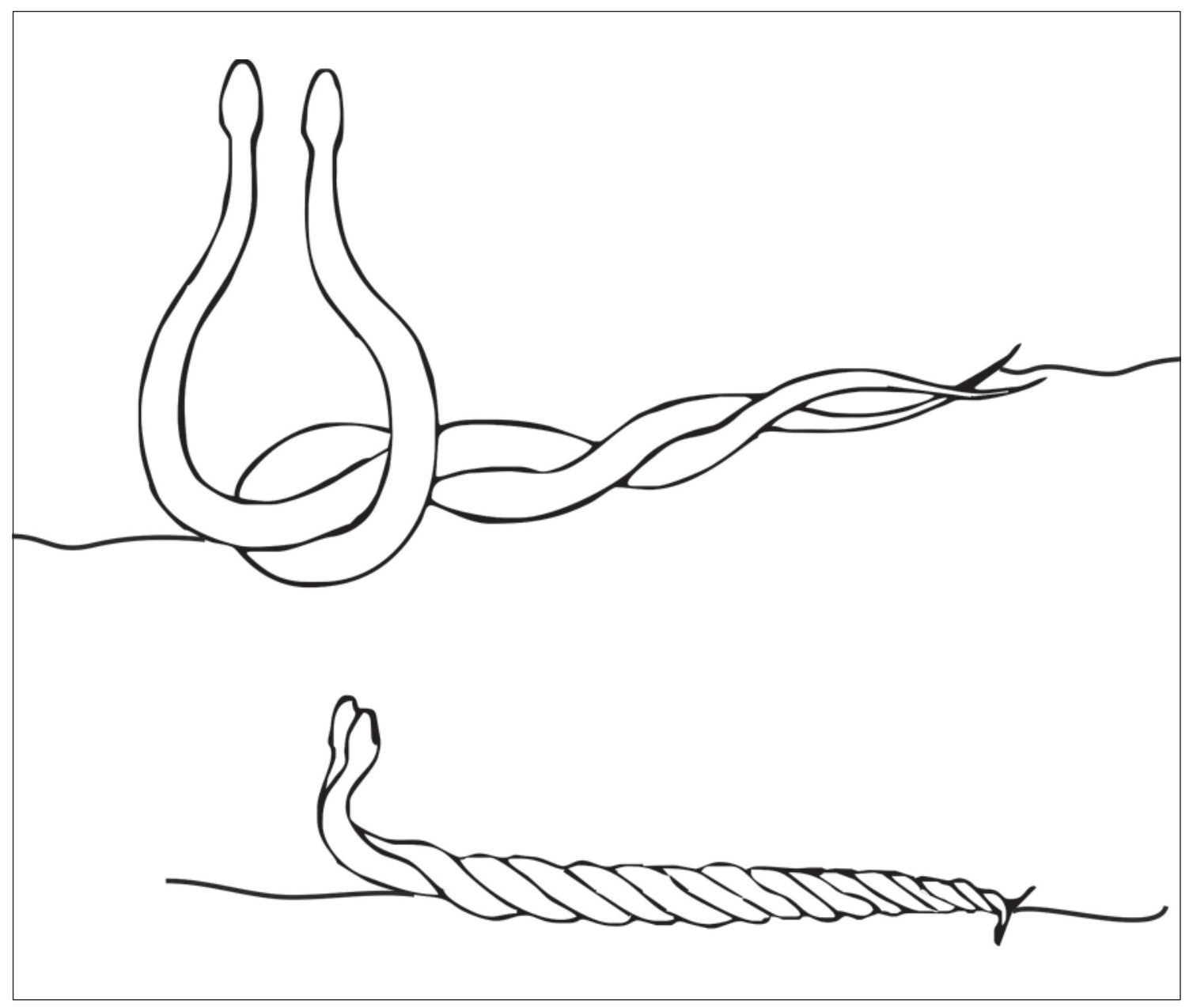

Figura 5. Diagrama que muestra el comportamiento de cortejo de culebras y la fusión visual de ambos individuos (modificado de Davis 1936). Figure 5. Diagram showing the snake mating ritual, with intertwining of the two individuals (modified from Davis 1936).

y como se observan en el momento de la cópula. En tal sentido, el examen de su ornamentación pintada puso en evidencia una discontinuidad en las líneas oscuras que rodean al recipiente y cuyo trazado define dos campos superpuestos pero diferenciados. Luego, se observó que la posición y el ángulo que presentan ambas cabezas entre sí, relacionadas lateralmente y una levemente ubicada por encima de la otra, recuerdan a los que exhiben muchas especies de ofidios durante la cópula (Davis 1936). Conviene señalar que los machos de las serpientes, como otros reptiles escamados, poseen órganos copuladores pares llamados hemipenes mediante los cuales transfieren el esperma a la hembra en una fecundación interna. En estos animales, el contacto de la genitalia y la tracción necesaria para lograr la cópula se genera por el enroscamiento de sus cuerpos, un componente del comportamiento de cortejo en muchas especies. En tal momento, diferenciar un organismo de otro resulta visualmente complejo y solo la presencia de dos cabezas indica que se trata de dos individuos (figs. 4 y 5 ).

Aceptando la propuesta de que la pieza es una representación naturalista de dos serpientes en cópula, se intentó una identificación sistemática de la especie. Haciendo hincapié en la presencia de algunos rasgos morfológicos y en la ausencia de otros, se concluyó que los individuos representados en cerámica pueden ser culebras (familias Colubridae o Dipsadidae). Tal propuesta se basa, en primer lugar, en la observación de que en ambas cabezas los ojos quedan definidos mediante incisiones horizontales, un rasgo que difiere 

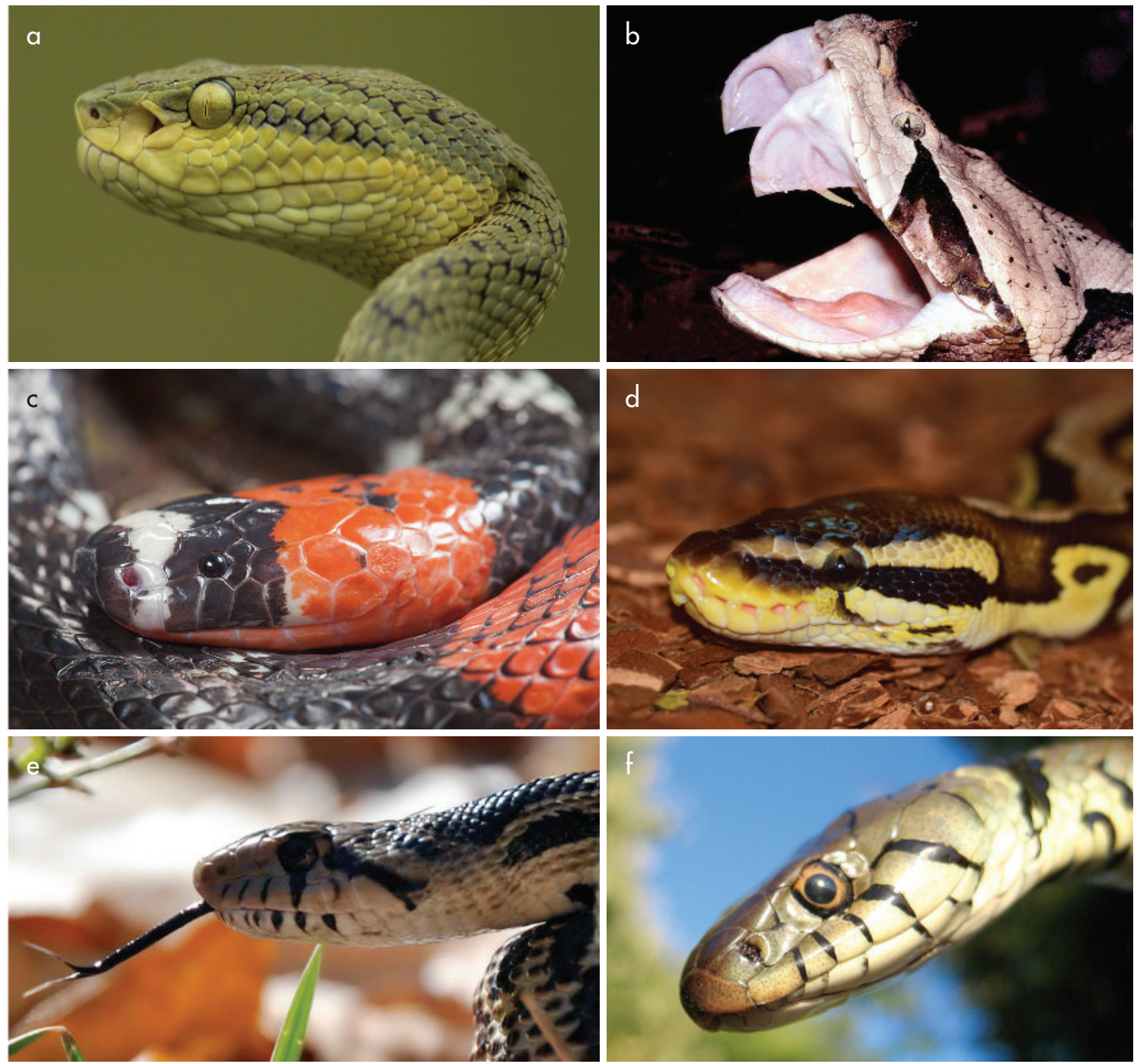

Figura 6. Región cefálica de ofidios de familias presentes en Argentina: a-b) Viperidae, con foseta loreal, pupila vertical y grandes dientes inoculadores de veneno; c) Elapidae, con cabeza poco diferenciada del cuerpo y coloración anillada característica; d) Boidae, con cabeza alargada y fosetas labiales; e-f) Colubridae, con pupila circular. (Fotografías: a) Supratim Laha; b) Brimac the Second; c) Frank Deschandol; d) de uso libre; e) Mohler Addison; f) Stephen Courtney). Figure 6. Heads of ophidia families present in Argentina: $\boldsymbol{a}$-b) Viperidae, with loreal pit, vertical pupil, and large venom-delivery fangs; $\boldsymbol{c}$ ) Elapidae, with undifferentiated head and body and typical colored rings; $d$ ) Boidae, with elongated head and labial pits; $\boldsymbol{e}-f$ ) Colubridae, with circular pupil. (Photos: $\boldsymbol{a})$ Supratim Laha; $\boldsymbol{b}$ ) Brimac the Second; c) Frank Deschandol; d) public domain; e) Mohler Addison; f) Stephen Courtney).

de la llamativa pupila vertical que poseen los vipéridos (yararás y cascabeles). La ausencia de fosetas sensitivas en ambas cabezas resultó igualmente diagnóstica, ya que no aparecen representadas o sugeridas ni las características fosetas loreales de los vipéridos ni las fosetas labiales propias de las boas. Por otro lado, la boca está representada como una incisión relativamente corta y no se observa ningún tipo de rasgo modelado o pintado que pudiera sugerir la presencia de dientes sobresaliendo de la misma, lo que lo aleja de los vipéridos, cuyos fuertes "colmillos" son muy conspicuos cuando abren ampliamente sus fauces para morder. También se descartó referir los individuos figurados a los elápidos (víboras de coral), dado que los ejemplares de cerámica no muestran las pequeñas cabezas típicas de esta familia ni su patrón característico de anillos concéntricos (fig. 6). 

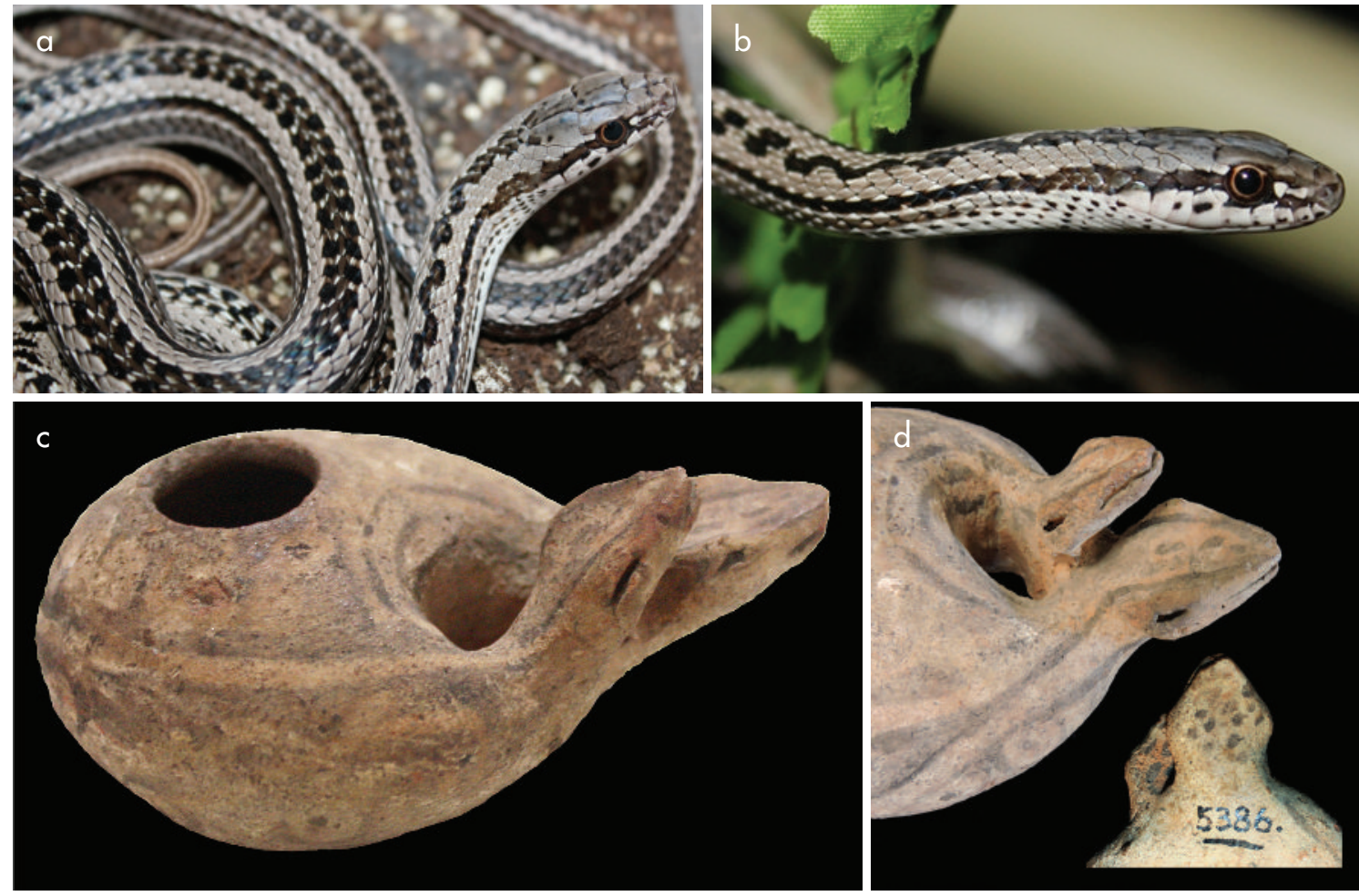

Figura 7. Vistas de la pieza MLP-Ar-(n)5386 y de ejemplares vivos de Philodryas psammophidea en los que puede observarse la repetición de un patrón semejante de rayas y manchas. (Fotografías: a-b) Johannes Marchand; c-d) de los autores). Figure 7. Pictures of living Philodryas psammophidea, showing the reiterated lines-and-spots pattern, and two views of the vessel MLP-Ar-(n)5386 (Photos: a-b) Johannes Marchand; $c$-d) the authors).

En cambio, la ausencia de fosetas y de colmillos visibles y la presencia de un patrón de manchas y rayas dorsolaterales a lo largo de todo el cuerpo e incluso en la cabeza, pueden observarse en ejemplares de Philodryas psammophidea. Vulgarmente conocida como "culebra rayada", esta especie se caracteriza por poseer un cuerpo delgado y estilizado, vientre amarillento o rosado y coloración dorsal gris claro con bandas longitudinales castaño oscuro, separadas por áreas claras a modo de bandas que recorren los flancos del cuerpo (Leynaud \& Bucher 1999: 31) (fig. 7).

\section{Distribución de la especie, antigüedad de la pieza}

Resulta interesante mencionar que en la actualidad no existe en el elenco herpetofaunístico de la zona de procedencia del vaso ninguna otra especie de ofidios con un patrón de bandas y manchas semejante al antes descrito, por lo que el detalle puesto en reproducirlo puede ser entendido como un esfuerzo del ceramista por identificar ejemplares de esta especie en particular. Pero, proponer que los individuos representados en una pieza arqueológica pertenecen a Philodryas psammophidea, hace necesario revisar la información disponible sobre el contexto cronológico y ambiental en que fue manufacturada, a fin de estimar si dicha propuesta es consistente con la paleobiogeografía de la especie.

El Santamariano ha sido identificado como un estilo cerámico tardío, de amplia distribución territorial y caracterizado por la repetición de ciertos elementos estructurales más allá de su variabilidad geográfica y temporal (Nastri 2001: 363). Si bien su exacta cronología y periodificación aún continúan siendo tema de discusión (Greco 2013), como ya se mencionó, su desarrollo ha sido ubicado en la primera mitad del segundo milenio, entre los siglos XI y xvi. Hasta donde se pudo indagar, no existe información publicada referida a la distribución de P. psammophidea para dicho período, pero trabajos recientes de análisis de datos moleculares indican que la especie habría existido en la región desde hace va- 
rios millones de años (Figueroa 2016) y se estima que su distribución hace mil años sería semejante a la que exhibe en la actualidad. En tal sentido, cabe indicar que se trata de una especie de culebra característica de la región fitogeográfica chaqueña, que se extiende desde el sur de Bolivia y oeste de Paraguay hasta el norte de Argentina, y desde el piedemonte cordillerano hasta el río Paraná (fig. 8). Específicamente en Argentina, la región abarca toda la provincia de Santiago del Estero y penetra en los valles del este de las provincias de Jujuy, Catamarca y La Rioja, y los del norte de San Luis (Cabrera \& Willink 1973), lo que define un ecosistema con una gran diversidad biológica. Las culebras en esta región comprenden alrededor de cuarenta y cinco especies agrupadas en una veintena de géneros (Leynaud \& Bucher 1999), pero solo P. psammophidea se distribuye por encima de los $500 \mathrm{msnm}$ (Gallardo 1979). El abolengo subandino de esta especie en particular resulta relevante para el análisis arqueológico, si se tiene en cuenta que la altitud promedio de los valles donde se concentran los hallazgos de cerámica santamariana ronda los $1600 \mathrm{msnm}$.

\section{CONSIDERACIONES FINALES}

Excede por mucho el interés de este artículo intentar dar cuenta de los motivos por los cuales el alfarero podría haber elegido representar esta especie de colúbrido en particular o los que llevaron a su elección como parte de un ajuar funerario. Más allá de su forma y decoración, cada pieza cerámica es el producto de una actividad intencionada cuyas características resultan de la articulación de la propuesta individual del alfarero con la de la cultura a la que pertenece. Naturalistas, fantásticas o abstractas, todas las representaciones codifican múltiples mensajes que la arqueología intenta descifrar abordando su estudio desde distintas perspectivas. Pero, el ejercicio desarrollado puso en evidencia el potencial de una mirada biológica al reconocimiento de las especies representadas en este tipo de producto cultural y las posibilidades de obtención de datos acerca de la interacción de poblaciones humanas y determinados grupos faunísticos. En el caso de la pieza analizada permitió elaborar una interpretación alternativa a su caracterización como representación de un animal fantástico de dos cabezas y proponer, en cambio, que se trata de dos individuos de una especie biológica en

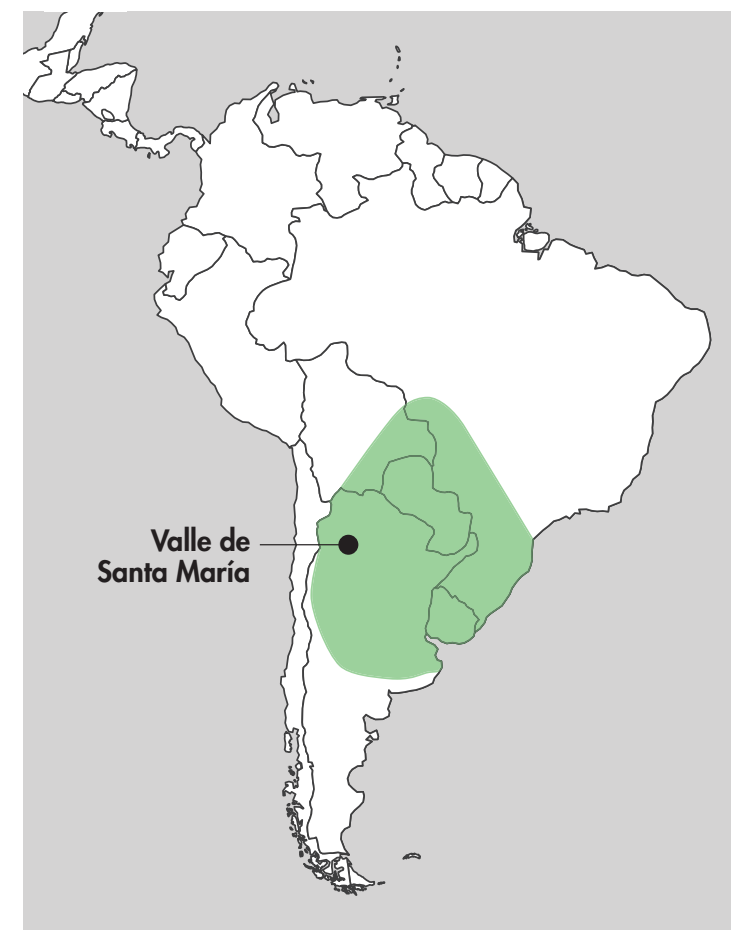

Figura 8. Demarcación de la extensión de la región biogeográfica chaqueña en América del Sur. Figure 8. Map showing the extent of the Chaqueña biogeographic region in South America.

particular, retratados en un momento específico de su ciclo vital. El grado de detalle taxonómico identificado en la pieza da cuenta de un contacto directo entre el ceramista y los organismos biológicos, lo que se estima constituye un aporte al análisis de un valioso corpus de información zoológica hasta ahora poco explorado en el Noroeste Argentino. Cabe esperar que el desarrollo de análisis sistemáticos semejantes sobre conjuntos arqueológicos más amplios enriquezca la interpretación de estos, y a su vez, proporcione datos biológicos que complementen y articulen con la información proporcionada por el registro óseo animal.

Indudablemente, por muy fidedigna que se presente, ninguna representación de un animal ofrece a la arqueología la misma información que sus restos orgánicos. Sin embargo, el detalle biológico exhibido por muchas piezas da cuenta del notable poder de observación de los ceramistas y de su capacidad de representar con precisión rasgos de la fauna que los rodeaba, aportando información novedosa a la exploración de los motivos y sentidos que el uso de sus imágenes tuvo en su contexto de origen. 
Agradecimientos A Javier Nastri y Guillermina Couso por su paciencia en la explicación de estilos cerámicos del NOA. A Diego Gobbo por su colaboración con el armado y procesamiento de imágenes. A la Dra. Helena Horta por su amabilidad ante nuestras consultas.

\section{NOTAS}

${ }^{1}$ Tal situación contrasta con lo observado en culturas arqueológicas de Perú y Bolivia, en las que abundan los recipientes cerámicos cuya morfología reproduce en tres dimensiones y en detalle las características de ejemplares de la fauna local, tanto en diseños naturalistas como en diseños con rasgos fantásticos (Benozzi 2005).

${ }^{2}$ Libreta de Wolters, IV expedición, Famabalasto, 7 de marzo 1922, página 26. Fondo Histórico-Documental de la División Arqueología, MLP.

\section{REFERENCIAS}

Aelianus, C. 1971 [250 AC]. Aelian on the characteristics of animals. Tomos I-XVII. Cambridge: Harvard University Press.

Амbrosetti, J. B. 1896. El símbolo de la serpiente en la alfarería funeraria de la región Calchaquí. Boletín del Instituto Geográfico Argentino XVII (cuadernos 4, 5 y 6): 3-14.

ARISTÓTELES. 1812 [350 AC]. On the generation of animals. En The works of Aristotle, translated from the greek. Volumen viII. Londres: Thomas Taylor.

Aschero, C., Podestá, M. M. \& García, L. 1991. Pinturas rupestres y asentamientos cerámicos tempranos en la puna argentina. Arqueología 1: 9-49.

Balesta, B. \& Zagorodny, N. 2000. Memorias e intimidades de una colección arqueológica. Relaciones de la Sociedad Argentina de Antropología xxv: 41-50.

Benozzi, E. 2005. El motivo zoomorfo en la cultura recuay: la colección de la Alcaldía de Chacas. <https://www. academia.edu/5688196/Benozzi_El_motivo_zoomorfo_en_la_cultura_recuay_la_colecci\%C3\%B3n_de_la_ Alcald\%C3\%ADa_de_Chacas> [consultado: 12-06-2019].

Berenguer, J. 2007. Comentarios. Boletín del Museo Chileno de Arte Precolombino 12 (2): 20-22.

Bugliani, M. \& Pereyra, L. 2012. Una aproximación estilístico-tecnológica a la cerámica polícroma 'Vaquerías' del Noroeste Argentino. Estudios Atacameños 43: 121-138.

Cabrera, Á. \& Willink, A. 1973. Biogeografía de América Latina. Washington: Secretaría General de la Organización de los Estados Americanos.

Clarkson, P. \& Valenzuela, D. 2015. Más allá de la identificación: enfoques teóricos y metodológicos para el estudio de representaciones visuales de plantas $y$ animales en arqueología <http://www2.udec.cl/xxcnach/?q=node/96> [consultado: 10-06-2019].
DAVIs, D. D. 1936. Courtship and mating behavior in snakes. Zoological Series of Field Museum of Natural History xx (22): 257-290.

FigueroA, A. 2016. Phylogenetic relationships and evolution of snakes. Tesis para optar al grado de Doctor, Universidad de Nueva Orleans, Nueva Orleans. <https://scholarworks.uno.edu/td/2222/?utm_source=scholarworks. uno.edu\%2Ftd\%2F2222\&utm_medium=PDF\&utm_ campaign=PDFCoverPages $>$ [consultado: 18-03-2019].

Gallardo, J. M. 1979. Composición, distribución y origen de la herpetofauna chaqueña. Monografías del Museo de Historia Natural de la Universidad de Kansas 7: 299-307.

GAllardo, J. \& YACOBACCIO, H. 2007. ¿Silvestres o domesticados? Camélidos en el arte rupestre del Formativo Temprano en el desierto de Atacama (Norte de Chile). Boletín del Museo Chileno de Arte Precolombino 12 (2): 9-31.

Greco, C. 2013. La cronología del Valle de Yocavil: escalas, datos, resultados. Arqueología 20: 11-37.

GonZÁLEZ, A. 1983. Notas sobre religión y culto en el Noroeste Argentino prehispánico. A propósito de unas figuras antropomorfas del Museo de Berlín. Baessler-Archiv 31: 212-282.

GonzÁlez, A. 1998. Cultura La Aguada. Arqueología y diseños. Buenos Aires: Filmediciones Valero.

Guzmán García, C. 2014. Diseño figurativo en los Andes antes de los incas. Investigaciones en Ciudad y Arquitectura 7 (1): 85-100.

Igareta, A., Giambelluca, R. \& López, G. 2017. Hacedores de animales. Cerámicas zoomorfas en colecciones del Museo de La Plata. Museo 29: 49-56.

Kligmann, D. \& DíAZ, E. 2007. Una primera aproximación a los motivos serpentiformes de la iconografía Aguada del NOA. Intersecciones en Antropología 8: 49-67.

Kligmann, D., Albino, A. \& Díaz, E. 2013. Anfisbenas para los dioses: zooarqueología de una ofrenda animal. De la puna a las sierras: avances y perspectivas en zooarqueología andina, A. D. Izeta \& G. L. Mengoni, Eds., pp. 89-120. Cambridge: BAR International Series 2564.

LAfone, S. 1908. Tipos de alfarería en la región diaguitacalchaquí. Buenos Aires: Imprenta de Coni Hermanos.

Leynaud, G. \& Bucher, E. 1999. La fauna de serpientes del Chaco sudamericano: diversidad, distribución geográfica y estado de conservación. Miscelánea de la Academia Nacional de Ciencias de Córdoba 98: 1-46.

NASTRI, J. 2001. El estilo cerámico santamariano de los Andes del Sur (siglos XI a XVI). Baessler-Archiv 47: 361-396.

NASTRI, J. 2008. Las figuras de largas cejas en la iconografía santamariana. Chamanismo, sacrificio y cosmovisión calchaquí. Boletín del Museo Chileno de Arte Precolombino 13 (1): 9-34.

NAstri, J. \& Coll, V. 2010. Variabilidad del estilo santamariano. En Actas del XV Congreso Nacional de Arqueología Argentina, A. Austral \& M. Tamagnini, Comps., Tomo III, pp. 357-366. Río Cuarto: Universidad Nacional de Río Cuarto. 
Núñez, L., Cartajena, I., Carrasco, C., De Souza, P. \& Grosjean, M. 2006. Patrones, cronología y distribución del arte rupestre arcaico tardío y formativo temprano en la cuenca de Atacama. Tramas en la piedra. Producción y usos del arte rupestre, M. Podestá \& D. Fiore, Eds., pp. 191-204. Buenos Aires: World Archaeological/Congreso-AINA-SAA.

RAFFINo, R. 1994. Expresiones artísticas indígenas del Museo de Ciencias Naturales de La Plata. La Plata: Fundación F. P. Moreno.

TARRAGó, M. 1989. Contribución al conocimiento arqueológico de las poblaciones de los oasis de San Pedro de Atacama en relación con los otros pueblos puneños, en especial el sector septentrional del Valle Calchaquí. Tesis Doctoral, Universidad Nacional de Rosario, Rosario, Argentina.

Troncoso, A. 2005. El plato zoomorfo/antropomorfo diaguita: una hipótesis interpretativa. Werken 6: 113-126.

Velandia, C. 2011. Anfisbenas y dragones en los Andes prehispánicos. <www.academia.edu/3697656/Anfisbenas_y_Dragones_en_los_Andes_Prehisp\%C3\%A1nicos> [consultado: 15-03-2019].

WALLACH, V. 2007. Axial bifurcation and duplication in snakes. Part I. A synopsis of authentic and anecdotal cases. Bulletin of the Maryland Herpetological Society 43 (2): 57-95. 